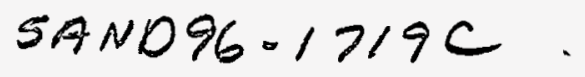

\title{
COMPETITION BETWEEN GETTERING BY IMPLANTATION-INDUCED CAVITIES IN SILICON AND INTERNAL GETTERING ASSOCIATED WITH $\mathrm{SIO}_{2}$
}

CONF- $961202-47$ PRECIPITATION SAND-96-1719C RECEIVED S.A. McHugo *,1, E.R. Weber*, S.M. Myers** and G.A.Petersen** · JAN 061997

* Dept. of Materials Science and Mineral Eng., University of California, Berkeley, CA 94720 ** Sandia National Laboratories, P.O. Box 5800, Albuquerque, NM 87185

${ }^{1}$ presently at: Advanced Light Source Center, Lawrence Berkeley National Laboratory, Berkeley, CA 94720, smchugo@rose.lbl.gov

\section{ABSTRACT}

The gettering behavior of $\mathrm{Cu}$ and $\mathrm{Fe}$ was investigated in $\mathrm{CZ}$ silicon which contained both internal-gettering sites in the bulk due to $\mathrm{SiO}_{2}$ precipitation and a device-side layer of cavities formed by He implantation and annealing. The objective was to quantify the effectiveness of impurity gettering at cavities relative to the widely used internal-gettering process. Both rapid thermal anneals and furnace anneals were used during the gettering sequences to reveal transient effects as well as the final, thermodynamically-equilibrated condition. For temperatures of 700 , 800 and $850^{\circ} \mathrm{C}$, the cavity gettering was observed to predominate over internal gettering as indicated both by the number of gettered atoms in the cavities and the residual solution concentration in the device region. The results are interpretated in detail by numerically solving the diffusion equation with sink-related source terms based on earlier, fundamental studies of the underlying mechanisms of internal and cavity gettering.

\section{INTRODUCTION}

Dissolved or metallic impurities can degrade silicon integrated circuit (IC) device yields when present in the near surface, active device region. This is such a critical issue that the IC community has set specifications for the reduction of metallic impurities down to $2.5 \times 10^{9}$ atoms $/ \mathrm{cm}^{3}[1]$. The exceptionally high diffusivity and solubility of $\mathrm{Cu}$ and $\mathrm{Fe}$ in silicon and their presence in many processing tools makes these impurities of particular interest. Additionally, $\mathrm{Cu}$ is being considered as an interconnect material because of its low electrical resistivity which creates a high potential for contamination [2].

A standard method to remove impurities from the device region is by internal gettering (IG) which uses oxygen precipitates and their related defects to getter impurities into the bulk and away from the active device region [3,4]. However, a obstacle exists for IG in that it requires an impurity supersaturation and significant diffusion of the impurity to the gettering site. These facts require IG anneals to have relatively low temperatures and long times which are not always commensurate with IC device processing. To satisfy the need for effective gettering at any temperature even for short anneals, so called "proximity" gettering treatments located near the device region which do not require an impurity supersaturation have been recently studied. Some of these methods have gettered $\mathrm{Cu}$ and $\mathrm{Fe}$ with modest success using heavily boron doped substrates for epitaxial wafers [5] or ion-implantation with boron, carbon, oxygen, $\mathrm{BF}_{2}$, nitrogen, germanium, neon, silicon or argon [6-10]. One of the most promising methods uses cavities formed by $\mathrm{He}$ or $\mathrm{H}$ ion implantation, which getter impurities on the cavity walls by chemisorption even when the nearby silicon matrix is not supersaturated with impurities and also by metal-silicide precipitation when the silicon is supersaturated [8,11-15]. This gettering process is robust in its gettering strength and stability for many metal impurities. In this paper, we study competitive gettering of $\mathrm{Fe}$ and $\mathrm{Cu}$ to cavities and internal gettering sites in order to

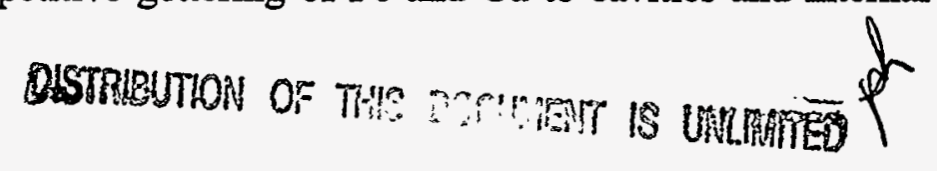

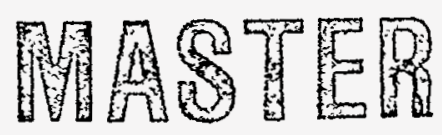




\section{DISCLAIMER}

This report was prepared as an account of work sponsored by an agency of the United States Government. Neither the United States Government nor any agency thereof, nor any of their employees, make any warranty, express or implied, or assumes any legal liabili. ty or responsibility for the accuracy, completeness, or usefulness of any information, apparatus, product, or process disclosed, or represents that its use would not infringe privately owned rights. Reference herein to any specific commercial product, process, or service by trade name, trademark, manufacturer, or otherwise does not necessarily constitute or imply its endorsement, recommendation, or favoring by the United States Government or any agency thereof. The views and opinions of authors expressed herein do not necessarily state or reflect those of the United States Government or any agency thereof. 


\section{DISCLAIMER}

Portions of this document may be illegible in electronic image products. Images are produced from the best available original document. 
assess the competitive process between these mechanisms and determine their individual gettering efficiencies and stabilities. Additionally, modeling results of the gettering process at both cavities and IG sites were contrasted with experimental data.

\section{PROCEDURE}

Boron doped $(\approx 10 \Omega-\mathrm{cm})<100>, \approx 500 \mu \mathrm{m}$ thick $\mathrm{CZ}$ silicon with an initial oxygen concentration of $\approx 9 \times 10^{17} / \mathrm{cm}^{3}$ was used for this study. Materials both with and without intentionally created internal gettering sites had an $\approx 10 \mu \mathrm{m}$ oxygen denuded zone created by a $1100^{\circ} \mathrm{C}, 5 \mathrm{hr}$ anneal. Internal gettering sites were formed by one of two methods: 1 ) a $700^{\circ} \mathrm{C}, 48$ hour oxygen precipitate nucleation anneal followed by a 8 hour precipitate growth step, referred to as the standard IG formation treatment and 2) a $700^{\circ} \mathrm{C}, 48$ hour nucleation treatment, followed by a thermal ramp from 700 to $900^{\circ} \mathrm{C}$ in $50^{\circ} \mathrm{C}$ increments for 30 minutes each and finally with a 8 hour precipitate growth anneal, referred to as the ramped IG formation treatment. The growth temperature was $950^{\circ} \mathrm{C}$ for the samples which were contaminated with $\mathrm{Cu}$ and $980^{\circ} \mathrm{C}$ for those with Fe. The ramp treatment allows for the formation of a high concentration of internal gettering sites related to oxygen precipitation by slowly increasing the critical radius of the oxygen precipitate [16]. $10^{14} \mathrm{Cu}$ atoms $/ \mathrm{cm}^{2}$ were introduced $\approx 0.1 \mu \mathrm{m}$ deep on both the front and back sides by a $150 \mathrm{keV}$ implantation after $\mathrm{He}$ implantation but just prior to the gettering heat treatments. Iron was introduced by thermal evaporation of iron on the sample backside followed by a 40 minute anneal at $980^{\circ} \mathrm{C}$ to form $\mathrm{FeSi}_{2}$ and uniformly distribute the $\mathrm{Fe}$ through the thickness of the samples. The $\mathrm{FeSi}_{2}$ was removed with polishing and etching after this heat treatment but before He implantation and any gettering anneals. All anneals were performed in a nitrogen atmosphere.

For the $\mathrm{Cu}$ gettering studies, $\mathrm{He}$ ions were implanted at $300 \mathrm{keV}(\approx 1.5 \mu \mathrm{m}$ deep) with a dose of $10^{17}$ atoms $/ \mathrm{cm}^{2}$. For the $\mathrm{Fe}$ gettering study, cavities were formed by He implantation at $1.5 \mathrm{MeV}$ with a dose of $10^{17}$ atoms $/ \mathrm{cm}^{2}$, resulting in a calculated He distribution centered near $5 \mu \mathrm{m}$ with a peak concentration of 6 atomic $\%$ and a root-mean-square spread of $\sim 0.2 \mu \mathrm{m}$ [17]. These He implantations alone produce cavities with diameters $\approx 1-3 \mathrm{~nm}$ [18]. The $\mathrm{Cu}$ was gettered by annealing the samples either at 700 or $800^{\circ} \mathrm{C}$ for 6 or 2 hours, respectively in a vacuum furnace ( $2 \times 10^{-7}$ torr) with a slow cool to room temperature. The Fe gettering treatment was carried out at either 700 or $850^{\circ} \mathrm{C}$ for 8 or 4 hours, respectively or by a rapid thermal annealing for 10 seconds at either 700 or $850^{\circ} \mathrm{C}$ which was terminated with a rapid quench $\left(\approx 1000^{\circ} \mathrm{C} / \mathrm{sec}\right)$ into ethylene glycol. The latter is referred to as the RTAQ treatment. The thermal history of the sample was recorded during this RTAQ treatment in order to correctly model the gettering process. During all gettering heat treatments He was expected to out-diffuse from the cavities with an accompanying cavity coalescence and enlargement. After significant anneal times, such as the $2,4,6$ or 8 hour anneals in these experiments, the cavity evolution slows and cavity diameters typically stabilize at $\approx 10-30 \mathrm{~nm}[18,19]$. For the 10 second anneals, the amount of released $\mathrm{He}$ will be small and the cavity microstructure will be somewhere between that found immediately after the He implantation and after significant anneal times. We believe that the chemically inert $\mathrm{He}$ gas inside the cavities will not significantly affect the reaction of $\mathrm{Fe}$ atoms with the cavity walls, however, this has not been directly shown.

The internal gettering site density was determined with laser scattering tomography (LST) and by etch pit analysis with a scanning electron microscope (SEM) operating in secondary electron mode. The material's interstitial oxygen concentration was monitored with Fourier Transform Infrared Spectroscopy (FTIR) via the new ASTM standard. Based on changes in the interstitial oxygen concentration, precipitate density and radii were calculated. Deep Level 
Transient Spectroscopy (DLTS) was used to measure dissolved Fe concentrations with a sensitivity of $\approx 2 \times 10^{11}$ atoms $/ \mathrm{cm}^{3}$. Secondary Ion Mass Spectroscopy (SIMS) was utilized to measure the $\mathrm{Fe}$ and $\mathrm{Cu}$ gettered at the cavities as well as the residual implanted $\mathrm{Cu}$ in the front and backside regions. Additionally, deep SIMS profiling, along with statistical analysis, was used to roughly estimate the $\mathrm{Cu}$ gettered at the IG sites.

The Fe gettering process was modeled by numerically solving the diffusion equation with source terms to take into account the reactions of the Fe with gettering sinks. The approach used has been described in detail elsewhere [15]. The reaction of Fe with the IG sites and the cavities was assumed to be diffusion controlled. The IG sites are assumed to be a relaxation-type gettering mechanism in which the IG site acts as a nucleation site for iron silicide and thus only allows the Fe concentration to approach solid solubility values when in equilibrium with the silicide [20] while the cavity sites are assumed to act as both a chemisorption-type gettering mechanism which can lower $\mathrm{Fe}$ concentrations below solubility values and a relaxation-type gettering mechanism. This description takes into account that cavities can nucleate the iron silicide phase as well as provide chemisorption sites. A more detailed description of this specific modeling is given in [21].

\section{RESULTS AND DISCUSSION}

A large difference in internal gettering site densities was realized between the precipitated oxygen samples and untreated samples. From LST measurements the precipitated and untreated samples had defect densities of $\approx 10^{10} / \mathrm{cm}^{3}$ and $\approx 7.1 \times 10^{7} / \mathrm{cm}^{3}$, respectively. It must be noted that these concentrations are total defect densities, not the absolute oxygen precipitate density. Samples which were subjected to the ramped IG formation treatment had etch pit densities of $\approx 5$ $8 \times 10^{9} / \mathrm{cm}^{3}$, correlating well with the LST results. From etch pit analysis in the SEM, the observed etch pits were only related to oxygen precipitates with no visible pits indicative of stacking faults or dislocation loops, [22], suggesting that the primary IG sites in these materials are oxygen precipitates. The lack of stacking faults or dislocation loops is most likely due to the relatively low temperature $\left(950^{\circ} \mathrm{C}\right)$ oxygen precipitate growth step. FTIR measurements revealed a significant drop in interstitial oxygen concentration for the precipitated samples to as low as $7 \times 10^{17} / \mathrm{cm}^{3}$ for the ramped IG formation treatment. From these measurements the precipitate densities and radii were calculated from Ham's law [23] and conservation of mass. Densities were similar to those measured by LST and etch pit analysis and radii were in the range of 30-40A. Overall, the standard and ramped IG formation anneals created a high density of oxygen precipitates compared to untreated samples which provides for a large difference in IG site densities between samples.

Figure 1 shows $\mathrm{Cu}$ and $\mathrm{Fe}$ accumulation in the cavities after $800^{\circ} \mathrm{C} / 2$ hour and $700^{\circ} \mathrm{C} / 8$ hour anneals, respectively. This accumulation was observed for all variations of samples, indicating the cavities effectively getter. The SIMS results are summarized in Tables 1 and 2. 

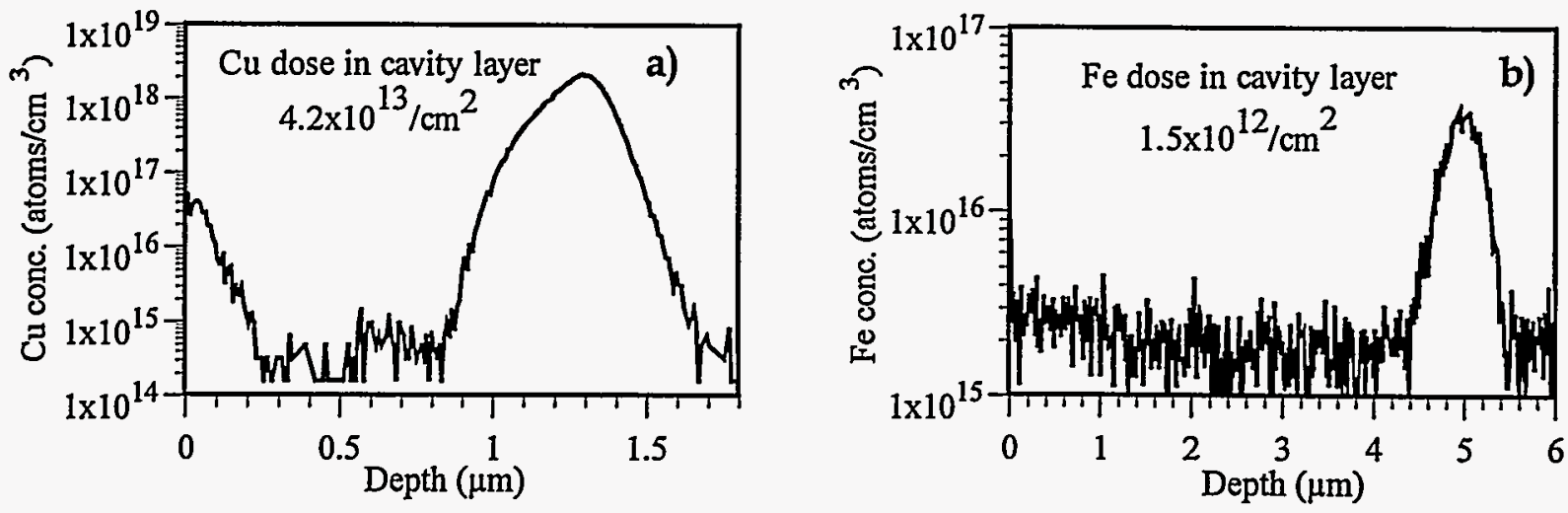

Figures la\&b: SIMS profiles of the near surface region showing a) $\mathrm{Cu}$ after a $800^{\circ} \mathrm{C}$ gettering anneal [cavities at $\approx 1.5 \mu \mathrm{m}$ ] and b) $\mathrm{Fe}$ after a $700^{\circ} \mathrm{C}$ gettering anneal [cavities at $\approx 5 \mu \mathrm{m}$ ].

\begin{tabular}{|c|c|c|c|c|c|}
\hline Sample & $\begin{array}{c}\text { Gettering } \\
\text { Temperature }\end{array}$ & $\begin{array}{c}\text { Cu-cavities } \\
\left(\mathbf{1 0}^{\mathbf{1 2}} \mathbf{c m}^{-2}\right)\end{array}$ & $\begin{array}{c}\text { Cu-bulk } \\
\left(\mathbf{1 0}^{\mathbf{2}} \mathbf{c m}^{-2}\right)\end{array}$ & $\begin{array}{c}\text { Cu-frontside } \\
\left(\mathbf{1 0}^{\mathbf{1 2}} \mathbf{c m}^{-2}\right)\end{array}$ & $\begin{array}{c}\text { Cu-backside } \\
\left(10^{12} \mathbf{c m}^{-2}\right)\end{array}$ \\
\hline with IG sites & $700^{\circ} \mathrm{C}$ & 39 & $2-10$ & 3.4 & 1.4 \\
& $800^{\circ} \mathrm{C}$ & 42 & - & 0.3 & 1.8 \\
\hline without IG sites & $700^{\circ} \mathrm{C}$ & 42 & $<\mathrm{DL}$ & 3.9 & 9.6 \\
& $800^{\circ} \mathrm{C}$ & 42 & - & 0.2 & 6.9 \\
\hline
\end{tabular}

Table 1: $\mathrm{Cu}$ doses in the cavities, frontside, backside and bulk after gettering anneals. $\mathrm{DL}=$ detection limit.

\begin{tabular}{|c|c|c|c|c|}
\hline $\begin{array}{c}\text { sample } \\
\text { getter anneal }\end{array}$ & $\begin{array}{c}\text { Fe in cavity } \\
\text { measured }\left(\mathrm{cm}^{-2}\right)\end{array}$ & $\begin{array}{c}\text { Fe in cavity } \\
\text { calculated }\left(\mathrm{cm}^{-2}\right)\end{array}$ & $\begin{array}{c}\text { Fe near-surf. } \\
\text { meas }\left(\mathrm{cm}^{-3}\right)\end{array}$ & $\begin{array}{c}\text { Fe near-surf. } \\
\text { calc }\left(\mathrm{cm}^{-3}\right)\end{array}$ \\
\hline no IG-no cav \#1 & - & - & $1.8 \times 10^{14}$ & $1.985 \times 10^{14}$ \\
\hline no IG-no cav \#2 & - & - & B.D.L. & $1.1 \times 10^{11}$ \\
\hline no IG-no cav \#3 & - & - & $1.9 \times 10^{14}$ & $1.95 \times 10^{14}$ \\
\hline no IG-no cav \#4 & - & - & $7.7 \times 10^{12}$ & $1.16 \times 10^{13}$ \\
\hline no IG-cav \#1 & $6.6 \times 10^{11}$ & $5.6 \times 10^{11}$ & N.M. & - \\
\hline no IG-cav \#2 & $2.4 \times 10^{12}$ & $3.7 \times 10^{12}$ & B.D.L. & $<1 \times 10^{10}$ \\
\hline no IG-cav \#3 & $5.6 \times 10^{12}$ & $8.9 \times 10^{11}, * 4.9 \times 10^{12}$ & $2.2 \times 10^{12}$ & $5.1 \times 10^{11}, * 2.8 \times 10^{12}$ \\
\hline no IG-cav \#4 & $5.6 \times 10^{12}$ & $3.5 \times 10^{12}, * 7.4 \times 10^{12}$ & B.D.L. & $9 \times 10^{10}, * 9 \times 10^{10}$ \\
\hline rp IG-no cav \#1 & - & - & $1.6 \times 10^{14}$ & $4.46 \times 10^{13}$ \\
\hline rp IG-no cav \#2 & - & - & B.D.L. & $<9 \times 10^{10}$ \\
\hline rp IG-no cav \#3 & - & - & $1.7 \times 10^{14}$ & $1.25 \times 10^{13}$ \\
\hline rp IG-no cav \#4 & - & - & $7.9 \times 10^{12}$ & $5.9 \times 10^{12}$ \\
\hline rp IG-cav \#1 & $3.0 \times 10^{11}$ & $3.4 \times 10^{11}$ & N.M. & - \\
\hline rp IG-cav \#2 & $1.5 \times 10^{12}$ & $5.9 \times 10^{11}$ & B.D.L. & $<1 \times 10^{10}$ \\
\hline rp IG-cav \#3 & $5.0 \times 10^{12}$ & $4.2 \times 10^{11}, * 4.4 \times 10^{12}$ & $9.5 \times 10^{11}$ & $2.4 \times 10^{11} * * 2.5 \times 10^{12}$ \\
\hline rp IG-cav \#4 & $4.1 \times 10^{12}$ & $2.0 \times 10^{12}, * 4.1 \times 10^{12}$ & B.D.L. & $9 \times 10^{10}, * 9 \times 10^{10}$ \\
\hline
\end{tabular}

Table 2: Measured and calculated values of $\mathrm{Fe}$ in the cavities $(\approx 5 \mu \mathrm{m})$ and dissolved in the near surface region $(\approx 1 \mu \mathrm{m})$ after gettering heat treatments. $\mathrm{rp}$ indicates IG sites formed by a ramped IG heat treatment. Gettering anneals are denoted by: $\# 1-700^{\circ} \mathrm{C}, 10$ seconds; $\# 2-700^{\circ} \mathrm{C}, 8$ hours; $\# 3-850^{\circ} \mathrm{C}, 10$ seconds and $\# 4-850^{\circ} \mathrm{C}, 4$ hours. B.D.L. indicates the Fe concentration was below the detection limit of DLTS $\left(<2 \times 10^{11} / \mathrm{cm}^{3}\right)$. N.M. indicates the Fe was not measurable by DLTS, due to poor diode quality. $A^{*}$ next to calculated values uses an assumption that $4 \times 10^{12} \mathrm{Fe}$ atoms $/ \mathrm{cm}^{2}$ were initially present in the cavities.

It should be noted that the amount of $\mathrm{Cu}$ and $\mathrm{Fe}$ accumulated in the cavities is far below the level corresponding to saturation of the cavity gettering sites, which for these experimental conditions is $\approx 10^{15}$ atoms $/ \mathrm{cm}^{2}$ [15]. The IG sites have little or no effect on the gettering of $\mathrm{Cu}$ or 
Fe to the cavities, indicating the cavities are the dominant gettering mechanism for our experiments and that the impurities at the cavity sites are stable even with the presence of IG sites. The cavities getter even with a small thermal load, showing great promise for this method of proximity gettering.

Extended $(15-20 \mu \mathrm{m})$ SIMS profiles of the $\mathrm{Cu}$ deep in the material's bulk were also taken after the cavities and $a \approx 150-200 \mu \mathrm{m}$ thickness of the silicon was removed. The profiles revealed the typical background noise of SIMS data but, in the case of the samples with IG sites, there are a number of spikes with large amplitudes, suggesting the presence of discrete agglomerations of $\mathrm{Cu}$ atoms within the matrix. Statistical analysis of this data gives the density of spikes at $\approx$ $2 \times 10 \% \mathrm{~cm}^{3}$ which is on the order of the measured density of IG sites and converts into a depthintegrated areal density of $\approx 2-10 \times 10^{12} \mathrm{Cu}$ atoms $/ \mathrm{cm}^{2}$ at IG sites [24]. One would not expect the $\mathrm{Cu}$ to become supersaturated and precipitate at IG sites in the presence of cavities with the heat treatments used in this study [15,24]. From this, it may be inferred that IG sites possess a relatively weak segregation-type gettering effect. Also in table 1 , are the $\mathrm{Cu}$ concentrations as measured with SIMS in the near front and backside regions where the $\mathrm{Cu}$ was originally implanted. The summation of the $\mathrm{Cu}$ in the cavities, the bulk, the front and backside regions does not equate to the original $\mathrm{Cu}$ introduced into the material. This find coincides with past research which indicates $\mathrm{Cu}$ rapidly evaporates from silicon at elevated temperatures [15].

DLTS was used to measure the dissolved Fe concentration $1-2 \mu \mathrm{m}$ from the surface for all Fe gettered samples. Since impurity removal from this region of the material is critical for proper IC device operation, these experiments were a stringent test for determining the effectiveness of gettering to cavities and IG sites. The measured Fe concentrations for all sample types are presented in Table 2. It is seen that the cavities significantly reduce the near surface $\mathrm{Fe}$ concentrations with or without the presence of IG sites. Considering the Fe solubility at $850^{\circ} \mathrm{C}$ is $\approx 8 \times 10^{12}$ atoms $/ \mathrm{cm}^{3}[20]$, the cavities have reduced the near surface Fe concentrations below the Fe solubility limits for both the short and long gettering anneals. Of particular interest, the cavities have held the Fe concentration below solubility with IG sites present even with a 4 hour $850^{\circ} \mathrm{C}$ anneal where significant Fe diffusion can take place. This result supports the concept that cavities restrain impurity concentrations below their solubility values even in the presence of relaxation-type gettering, i.e. the cavities act as stable gettering sites. Samples with only IG sites require long gettering anneals to reduce the Fe concentration to the solubility value while the short anneals only slightly reduced the initial Fe concentration. The long anneals are required simply because of the greater distance required for Fe diffusion and the dispersed nature of the IG sites compared to the nearly continuous plane of cavity gettering sites. Taken together, these results are clear evidence that the proximity-segregation-type gettering of the cavities is preferred to standard gettering at IG sites.

Also shown in Table 2 are the results obtained from modeling of the Fe gettered to the cavities and the remaining dissolved $\mathrm{Fe}$ at $1 \mu \mathrm{m}$. In the majority of the cases, good semiquantitative consistency is observed for the areal density of $\mathrm{Fe}$ in the cavities as well as for the near-surface dissolved Fe concentration. The exception to this is for the samples subjected to the short furnace anneal at $850^{\circ} \mathrm{C}$. Even if one considers the maximum depth at which $\mathrm{Fe}$ can diffuse to reach the cavities during the 10 second $850^{\circ} \mathrm{C}$ anneal, the high $\mathrm{Fe}$ found in the cavities is not physically possible. This suggests $\mathrm{Fe}$ contamination has occurred at some stage of the sample processing. In fact, from a careful accounting of all the $\mathrm{Fe}$ in the samples after the gettering anneals, we have found that additional Fe is observed in samples with cavities [21]. Bearing this within the context of the modeling, this presumed contamination was accounted for by assuming $4 \times 10^{12} \mathrm{Fe}$ atoms $/ \mathrm{cm}^{2}$ is present in the cavities at time zero. Results from this 
modification are shown with asterisks in Table 2 and are seen to produce improved agreement not only for the areal density of $\mathrm{Fe}$ in the cavities but also for the near-surface dissolved concentrations.

From these results it is apparent that the cavities act as more efficient gettering sites. This is due to the fact that 1) the cavities are located closer to the device region than IG sites, 2) the cavities form an approximately continuous sheet of gettering sites as compared to IG sites which are relatively widely dispersed, and 3) the cavities getter by chemisorption, a segregation-type mechanism not dependent on supersaturation. The first two issues greatly enhance the kinetics of gettering for cavities while the last gives a thermodynamic advantage to the cavities allowing for highly effective gettering. Together, these facts allow for short anneals over a wide temperature range to drastically decrease impurity concentrations in the device region with cavity gettering.

\section{CONCLUSIONS}

He implantation-induced cavities effectively getter $\mathrm{Cu}$ and $\mathrm{Fe}$ in silicon even in the presence of internal gettering sites. The gettering action is dominated by the cavities. With cavities, the $\mathrm{Fe}$ concentration in this near surface region is rapidly decreased to below $\mathrm{Fe}$ solubility values at the gettering temperatures. Internal gettering sites do not getter as effectively and do not reduce concentrations below solubility values. This disparity in effectiveness is due to the location and physical mechanism of each gettering technique. A semiquantitative description of the gettering process was achieved with theoretical modeling. These results indicate that these cavities are an excellent means for proximity getering of metal impurities from IC device regions.

\section{ACKNOWLEDGMENTS}

The authors would like to thank Dr. M. Werner and Dr. Kissinger for LST measurements and Dr. F.G. Kirscht, Dr. T. Heiser and H. Hieslmair for intriguing discussions. The SIMS work was carried out at Charles Evans and Associates. This work was supported by the U.S. D.O.E. under contract No. DE-AC04-94AL85000 and the Director, Office of Basic Energy Research, Materials Science Division, U.S. D.O.E. contract No. DE-AC03-76SF00098.

\section{REFERENCES}

1. The National Technology Roadmap for Semiconductors (Semiconductor Industry Assoc., San Jose, CA, 1994), p. 110

2. Materials Research Society Bulletin (Materials Research Society, Pittsburgh, PA, August 1994)

3. W.K. Tice and T.Y. Tan, Mater. Res. Soc. Symp. Proc. 2, 367 (1981)

4. D. Gilles, E.R. Weber and S.K. Hahn, Phys. Rev. Lett. 64, 196 (1990)

5. M. Aoki, A. Itakura and N. Sasaki, Appl. Phys. Lett. 68, 51 (1995)

6. H. Wong, N. W. Cheung and P. K. Chu, Appl. Phys. Lett. 52, 889 (1988)

7. W. Skorupa, R. Kogler, K. Schmalz, P. Gaworzewski, G. Morgenstren and H. Syhre, Nuc. Instr. and Meth. in Phys. Res. B 74, 70 (1993)

8. M. H. F. Overwijk, J. Politiek, R. C. M. d. Kruif and P. C. Zalm, Nuc. Instr. and Meth. in Phys. Res. B 96, 257 (1995)

9. C. J. Barbero, J. W. Corbett, C. Deng and Z. Atzmon, J. Appl. Phys. 78, 3012 (1995)

10. P. A. Stolk, J. L. Benton, D. J. Eaglesham, D. C. Jacobson, J.-Y. Cheng, J. M. Poate, S. M. Myers and T. E. Haynes, Appl. Phys. Lett. 68, 51 (1995) 
11. S. M. Myers, D. M. Follstaedt, D. M. Bishop and J. W. Medernach, in: Semiconductor Silicon, 7th International Symposium on Silicon Materials Science \& Tech., edited by H.R. Huff, W. Bergholz and K. Sumino, (The Electrochemical Society, Pennington, NJ, 1994, p. 808-819

12. J. Wong-Leung, E. Nygren and J. S. Williams, Appl. Phys. Lett. 67, 416 (1995)

13. V. Raineri, A. Battaglia and E. Rimini, Nuc. Instr. and Meth. in Phys. Res. B 96, 249 (1995)

14. S. M. Myers, G. A. Petersen and C. H. Seager, J. Appl. Phys. 80, 3717 (1996)

15. S. M. Myers and D. M. Follstaedt, J. Appl. Phys. 79, 1337 (1996)

16. S.A. McHugo, M. Mizuno, F.G. Kirscht and E.R. Weber, Appl. Phys. Lett. 66, 2840 (1995)

17. J.F. Ziegler, J.P. Biersack and U. Littmark, in: "The Stopping and Range of Ions in Solids", (Pergamon, New York, 1985)

18. C.C. Griffioen, J.H. Evans, P.C. de Jong and A. Van Veen, Nucl. Instrum. Methods B 27, 417 (1987)

19. D.M. Follstaedt, S.M. Myers, G.A. Peterson and J.W. Medernach, J. Elec. Matls. 25, 151 (1996)

20. E.R. Weber, Appl. Phys. A 30, 1 (1983)

21. S.A. McHugo, E.R. Weber, S.M. Myers and G.A. Petersen, submitted to J. Appl. Phys., 1996

22. D. C. Miller and G. A. Rozgonyi, in: "Handbook on Semiconductors", ed. S.P. Keller (NorthHolland Publishing Company, 1980) p. 217-246.

23. F.S. Ham, J. Phys. Chem. Solids 6, 335 (1958)

24. S.A. McHugo, E.R. Weber, S.M. Myers and G.A. Petersen, "Competitive gettering of copper in Czochralski silicon by implantation-induced cavities and internal gettering sites", Appl. Phys. Lett., Nov. 11, 1996 